\title{
Duration of hemodynamic effects of crystalloids in patients with circulatory shock after initial resuscitation
}

Thieme Souza Oliveira Nunes, Renata Teixeira Ladeira, Antônio Tonete Bafi, Luciano Cesar Pontes de Azevedo, Flavia Ribeiro Machado and Flávio Geraldo Rezende Freitas ${ }^{*}$

\begin{abstract}
Background: In the later stages of circulatory shock, monitoring should help to avoid fluid overload. In this setting, volume expansion is ideally indicated only for patients in whom the cardiac index $(\mathrm{Cl})$ is expected to increase. Crystalloids are usually the choice for fluid replacement. As previous studies evaluating the hemodynamic effect of crystalloids have not distinguished responders from non-responders, the present study was designed to evaluate the duration of the hemodynamic effects of crystalloids according to the fluid responsiveness status.

Methods: This is a prospective observational study conducted after the initial resuscitation phase of circulatory shock ( $>6 \mathrm{~h}$ vasopressor use). Critically ill, sedated adult patients monitored with a pulmonary artery catheter who received a fluid challenge with crystalloids (500 mL infused over $30 \mathrm{~min}$ ) were included. Hemodynamic variables were measured at baseline (T0) and at $30 \mathrm{~min}$ (T1), $60 \mathrm{~min}$ (T2), and $90 \mathrm{~min}$ (T3) after a fluid bolus, totaling 90 min of observation. The patients were analyzed according to their fluid responsiveness status (responders with $\mathrm{Cl}$ increase $>15 \%$ and non-responders $\leq 15 \%$ at $\mathrm{T} 1$ ). The data were analyzed by repeated measures of analysis of variance.

Results: Twenty patients were included, 14 of whom had septic shock. Overall, volume expansion significantly increased the Cl: $3.03 \pm 0.64 \mathrm{~L} / \mathrm{min} / \mathrm{m}^{2}$ to $3.58 \pm 0.66 \mathrm{~L} / \mathrm{min} / \mathrm{m}^{2}(p<0.05)$. From this period, there was a progressive decrease: $3.23 \pm 0.65 \mathrm{~L} / \mathrm{min} / \mathrm{m}^{2}$ ( $p<0.05$, T2 versus T1) and $3.12 \pm 0.64 \mathrm{~L} / \mathrm{min} / \mathrm{m}^{2}(p<0.05$, period T3 versus T1). Similar behavior was observed in responders (13 patients), $2.84 \pm 0.61 \mathrm{~L} / \mathrm{min} / \mathrm{m}^{2}$ to $3.57 \pm 0.65 \mathrm{~L} / \mathrm{min} / \mathrm{m}^{2}$ $(p<0.05)$ with volume expansion, followed by a decrease, $3.19 \pm 0.69 \mathrm{~L} / \mathrm{min} / \mathrm{m}^{2}(p<0.05$, T2 versus T1) and $3.06 \pm$ $0.70 \mathrm{~L} / \mathrm{min} / \mathrm{m}^{2}(p<0.05, \mathrm{~T} 3$ versus T1). Blood pressure and cardiac filling pressures also decreased significantly after $\mathrm{T} 1$ with similar findings in both responders and non-responders.
\end{abstract}

Conclusions: The results suggest that volume expansion with crystalloids in patients with circulatory shock after the initial resuscitation has limited success, even in responders.

Keywords: Fluid; Fluid responsiveness; Fluid resuscitation; Crystalloids; Circulatory shock; Hemodynamics

\footnotetext{
* Correspondence: flaviogrf@yahoo.com.br

Disciplina de Anestesiologia, Dor e Terapia Intensiva, Universidade Federal de

São Paulo, Rua Napoleão de Barros 715 - $5^{\circ}$ andar, São Paulo SP 04024-900,

Brazil
} 


\section{Background}

Intravascular fluid administration is the first-line intervention for the restoration of hemodynamic stability in critically ill patients [1]. The expected response to fluid infusion is an increase in venous return leading to an augmentation of cardiac output (CO) through the Frank-Starling mechanism [2]. However, only half of all hemodynamically unstable patients are preload-responsive [3]. This phenomenon could be particularly important in patients who are in the intensive care unit (ICU) for several hours or days after the initial resuscitation. At this stage, especially if a lung is injured, positive fluid balance becomes a major concern. In this case, it is recommended to use predictors of fluid responsiveness to distinguish between patients who can benefit from volume expansion (responders) and those in whom fluid loading can be futile and even deleterious (non-responders) [4].

However, even in responders, using fluids after the initial resuscitation to treat hypotension or indices of inadequate tissue perfusion could be inappropriate. Two factors justify this concern: First, fluid administration can lead to an increased fluid balance, which is associated with a worse outcome in ICU patients [5,6]. Second, isotonic crystalloid solutions, usually the choice for fluid replacement, have a limited effect on plasma volume. In theory, after a short period of balance, only approximately $20 \%$ of an intravenously infused crystalloid solution will remain in the intravascular space to support plasma volume [7].

Studies designed to examine fluid responsiveness only address the immediate hemodynamic response to a fluid challenge. Moreover, previous studies evaluating the hemodynamic effect of crystalloids have not distinguished responders from non-responders. The present study aimed to evaluate the short-term hemodynamic effects of volume expansion with crystalloids after the initial resuscitation of circulatory shock in patients receiving vasopressors and to compare these effects in responders and non-responders.

\section{Methods}

This observational study was conducted in a 35-bed mixed ICU in a university hospital. The institutional Research and Ethics Committee (Universidade Federal de São Paulo) approved the study, and informed consent was waived due to its purely observational nature.

We prospectively included adult patients with circulatory shock who received one fluid challenge with crystalloids (Ringer's lactate or sodium chloride $0.9 \%$ solution, $500 \mathrm{~mL}$ infused over $30 \mathrm{~min}$ ) indicated for inadequate tissue perfusion by the attending physician. Only patients treated with vasopressors for at least $6 \mathrm{~h}$, under mechanical ventilation, receiving continuous sedation (Ramsay score 5 to 6), and monitored with an arterial catheter and a pulmonary artery catheter (Edwards Lifesciences, Irvine, CA, USA) were eligible for study inclusion. We excluded patients in whom the primary cause of hypotension was active bleeding (suspected or confirmed), burn injury, and cardiogenic shock, defined as cardiac index $(\mathrm{CI})<1.8 \mathrm{~L} /$ $\mathrm{min} / \mathrm{m}^{2}$ without support and pulmonary artery occlusion pressure $\geq 18 \mathrm{mmHg}$.

The patients were followed during fluid infusion (30 min) and for $60 \mathrm{~min}$ after. Throughout this observational period, if the attending physician changed ventilator parameters, doses of the sedative, inotropic and vasopressor medications or administered a new volume expansion, the patient was excluded from the analysis.

As part of the routine care, we registered a complete set of hemodynamic and respiratory measurements, including arterial and mixed venous blood gases, and hemoglobin and arterial lactate levels at the beginning (T0) and end of the volume expansion (T1). Only hemodynamic measurements were registered at $60 \mathrm{~min}$ (T2) and $90 \mathrm{~min}$ (T3). Thus, the study has four different time points: baseline (T0), $30 \mathrm{~min}$ (T1), $60 \mathrm{~min}$ (T2), and $90 \mathrm{~min}$ (T3) after the fluid bolus, totaling 90 min of observation. Patients who did not have laboratory samples collected before and after the fluid infusion were excluded from the analysis.

The CI was measured using a semi-continuous thermodilution technique considering the average value of four consecutive measurements from the STAT mode screen of the Vigilance ${ }^{\circ}$ monitor (Edwards Lifesciences, Irvine, CA, USA). We also measured the pulse pressure variation $(\mathrm{PPV})$ in patients without limitations to this assessment, with a multiparameter bedside monitor (DX 2020, Dixtal, São Paulo, Brazil) using the automatic method $[8,9]$. All pressures were determined using the cursor line of the bedside monitor screen. The reference point for right atrial pressure (RAP) and pulmonary artery occlusion pressure (PAOP) was the base of the ' $a$ ' wave at the end-expiration phase with the zero reference level settled at the mid-chest and the head of the bed elevated at approximately $30^{\circ}$.

\section{Statistical analysis}

Data are expressed as numbers (\%), means \pm standard deviation (SD), or medians and interquartile ranges (25th to 75th percentile), as appropriate. Changes in CI after the fluid infusion were expressed as percentages. The distribution of continuous variables was assessed by the ShapiroWilk test.

A one-way repeated measures analysis of variance (ANOVA) was used to compare the hemodynamic variables in different time points (T0, T1, T2, and T3). Second, the patients were divided into two subgroups according to the percent increase in $\mathrm{CI}$ in response to volume expansion: 'responders' had a CI increase of at least 15\%, whereas 'non-responders' had a CI increase of less than 15\%. A two-way repeated measure ANOVA (to include a 
subgroup interaction effect) was also conducted. We used Bonferroni adjustment for multiple comparisons.

When only measurements at T0 and T1 were available (hemoglobin, lactate, and mixed venous oxygen saturation), we used Mann-Whitney $U$ test or a $t$ test to compare responders and non-responders at baseline and Wilcoxon's rank-sum test or a paired $t$ test to assess the effects of intravascular volume expansion.

We used SPSS version 17.0 for Windows (SPSS Inc., Chicago, IL, USA). The results with $p$ values of $<0.05$ were considered to be significant.

\section{Results}

From September 2011 to January 2013, 84 patients with circulatory shock were monitored with a pulmonary artery catheter in the ICU, of whom 20 patients were included (Figure 1).

The circulatory shock was secondary to sepsis $(n=14)$, major surgery $(n=5)$, or multiple trauma $(n=1)$. The median duration of vasopressor use before inclusion was 25 (19.5 to 34.0) h. The fluid balance from the time when vasopressor treatment was initiated to volume expansion was $7,217(6,345$ to 8,545$) \mathrm{mL}$. There was no difference between responders and non-responders regarding the duration of shock $(p=0.59)$ and fluid balance $(p=0.81)$. Patient characteristics are listed in Table 1.

The indications for volume expansion were hyperlactatemia (30\%), hypotension (20\%), clinical signs of poor skin perfusion $(20 \%)$, reduce vasopressors $(20 \%)$, and oliguria (10\%). The diuresis during study period was 37.50 (0.00 to 97.50) $\mathrm{mL}$, with no differences between responders and non-responders $(p=0.77)$.
Table 1 Patient characteristics at baseline

\begin{tabular}{|c|c|}
\hline Patient characteristic & Data \\
\hline Age (years) & $63.7 \pm 14.2$ \\
\hline Gender [male (\%)] & $16(80)$ \\
\hline APACHE ॥ & $21.50(18.0$ to 26.0$)$ \\
\hline SOFA & $10.5(9.0$ to 12.0$)$ \\
\hline PEEP $\left(\mathrm{cm} \mathrm{H}_{2} \mathrm{O}\right)$ & $8.0(5.0$ to 10.0$)$ \\
\hline $\mathrm{FiO}_{2}(\%)$ & $40(40$ to 50$)$ \\
\hline Tidal volume $(\mathrm{mL})$ & $487 \pm 95.1$ \\
\hline Cstat $\left(\mathrm{mL} / \mathrm{cm} \mathrm{H}_{2} \mathrm{O}\right)$ & $39.2 \pm 13.5$ \\
\hline $\mathrm{PaO}_{2} / \mathrm{FiO}_{2}$ & $206.6 \pm 72.9$ \\
\hline Time of vasopressor use (h) & $25.0(19.5$ to 34.0$)$ \\
\hline Fluid balance $(\mathrm{mL})^{a}$ & $7,217(6,345$ to 8,545$)$ \\
\hline \multicolumn{2}{|l|}{ Causes of shock } \\
\hline Sepsis $[n(\%)]$ & $14(70)$ \\
\hline Major surgery $[n(\%)]$ & $5(25)$ \\
\hline Multiple trauma [n (\%)] & $1(5)$ \\
\hline \multicolumn{2}{|l|}{ Catecholamine infusion } \\
\hline Norepinephrine, $\mu \mathrm{g} / \mathrm{kg} / \mathrm{min}(n=20)$ & $0.33(0.21$ to 0.83$)$ \\
\hline Epinephrine, $\mu \mathrm{g} / \mathrm{kg} / \min (n=5)$ & $0.26(0.14$ to 0.35$)$ \\
\hline Dobutamine, $\mu \mathrm{g} / \mathrm{kg} / \min (n=5)$ & $6.0(5.1$ to 7.1$)$ \\
\hline Survivors (ICU) $[n(\%)]$ & $7(35)$ \\
\hline
\end{tabular}

APACHE II, Acute Physiology and Chronic Health Evaluation II; SOFA, Sequential Organ Failure Assessment score; PEEP, positive end-expiratory pressure; $\mathrm{FiO}_{2}$, fraction of inspired oxygen; $\mathrm{C}$ stat, static respiratory compliance; $\mathrm{PaO}_{2}$, partial pressure of oxygen; ICU, intensive care unit. ${ }^{\mathrm{a}}$ From shock to fluid infusion. Quantitative variables are expressed as means (SD) or medians (IQR 25th to 75th percentile).

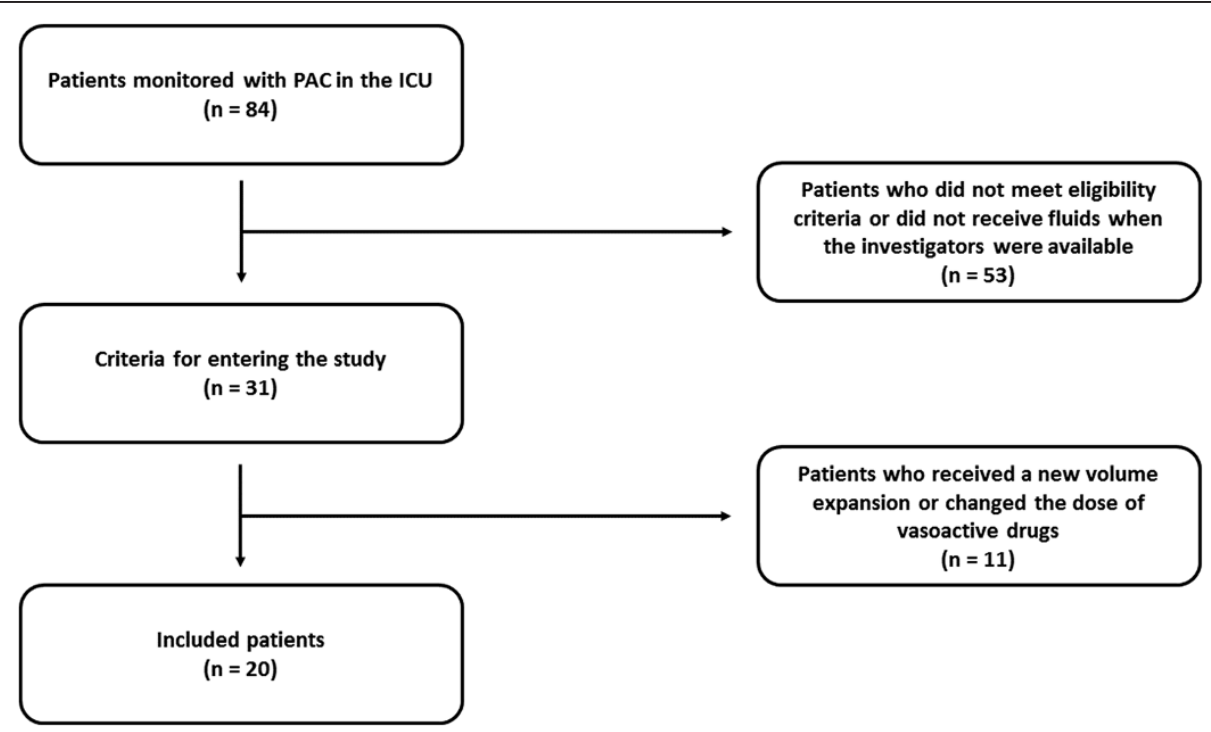

Figure 1 Study flowchart. PAC, pulmonary artery catheter; ICU, intensive care unit. 
Overall, CI increased significantly after volume expansion; however, in T3, CI decreased to the baseline values (Figure 2). Cardiac filling pressures and mean arterial pressure (MAP) also increased significantly in $\mathrm{T} 1$ and decreased after volume expansion (T2 and T3) (Table 2).

Thirteen patients were considered to be volume responders, as their CI increased more than 15\%. CI did not change over time in non-responders group, whereas in responders $\mathrm{CI}$ changed significantly: after an initial increase from $\mathrm{T} 0$ to $\mathrm{T} 1$, there was a reduction in $\mathrm{T} 2$ and T3. Cardiac filling pressures and MAP were similar between responders and non-responders over time. These variables decreased after volume expansion (T2 and T3) toward baseline values. Responders and non-responders showed no significant change in heart rate (HR) over time (Table 3).

All patients were in sinus rhythm, and only one had ventricular extrasystoles not allowing automatic PPV measurement. We also did not record PPV in other 14 patients because of spontaneous ventilation or ventilation with low tidal volume. Thus, PPV could be registered only in five patients. The four responders at baseline were not fluid-responsive at T1 (PPV < 12\%).

\section{Discussion}

The main finding of our study was that CI decreased toward baseline values $60 \mathrm{~min}$ after fluid infusion. Even in responders, the hemodynamic changes nearly disappeared in this period. The results strengthen the body of evidence that shows a short hemodynamic effect after volume expansion with crystalloids.

As there were no acute fluid losses, the main finding of our study has some possible explanations. First, crystalloids have limited intravascular volume effect, as suggested by volume kinetics studies of Ringer's solution [10-13]. This has been demonstrated even in normal vascular endothelial conditions. A study in healthy volunteers demonstrated that $68 \%$ of the saline infused $(1,000 \mathrm{~mL}$ over $60 \mathrm{~min}$ ) had escaped from the intravascular to the

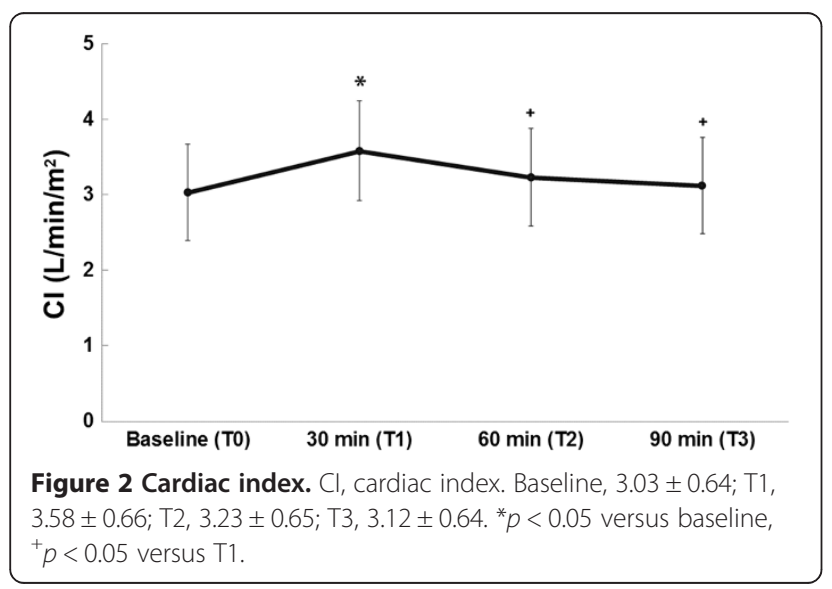

extravascular space at the end of infusion, as estimated from hematocrit/hemoglobin changes [12]. According to another study, in healthy volunteers who received lactated Ringer's solution (1,000 $\mathrm{mL}$ over 5 to $7 \mathrm{~min}$ ) after blood withdrawal, the peak increase in the intravascular volume occurred immediately after completion of infusion (630 \pm $127 \mathrm{~mL}$ ), and the intravascular volume expanding effect declined rapidly after its initial peak (only $403 \pm 88 \mathrm{~mL}$ by $15 \mathrm{~min}$ ) [13]. Second, under inflammatory conditions, such as sepsis, surgery, or trauma, the damage of the endothelial glycocalyx decreases vascular barrier function and leads to protein extravasation $[14,15]$. In these settings, the hemodynamic effects of crystalloid may be smaller. In postoperative hypovolemic patients, Ringer's solution $(10 \mathrm{~mL} / \mathrm{kg}$ over $30 \mathrm{~min})$ significantly improved hemodynamics at the end of volume loading, but this effect completely disappeared at $120 \mathrm{~min}$ [16]. One important point is that there might be different behaviors among our patients, depending on the origin of shock, the degree of vasodilation, the supposed degree of capillary leak, and the shock severity.

A number of experimental and clinical studies, generally comparing crystalloids with colloid solutions, have reached similar conclusions through different monitoring tools and endpoints [12,13,16-20]. In these studies, the hemodynamic effects of colloids lasted longer than those of crystalloids. In general, colloid administration restores hemodynamic stability more rapidly and with less volume in a variety of clinical conditions [17-20]. Despite theoretical benefits favoring colloids over crystalloids to achieve resuscitation endpoints, this advantage is not as clear in clinical application [21,22]. Comparisons in patients with capillary leak show that the ratio between required volumes in the crystalloid and colloid is in a range between 1 and 2 (not threefold or higher ratio as recommended by textbooks) [21]. Moreover, there are concerns about the safety of synthetic colloids [23-26]. Thus, we chose to evaluate only the use of fluid challenges with crystalloids in this study.

Rather than increasing the plasma volume or reaching static parameters of preload, the main reason for intravascular fluid administration is to increase stroke volume. If the fluid challenge does not increase stroke volume, the volume loading is useless to the patient [1]. In our sample, volume expansion led to an immediate increase in cardiac filling pressures in all patients and significantly increased $\mathrm{CI}$ in a subset of them (responders). This result aligns with studies designed to examine fluid responsiveness [27-29]. However, these studies only describe the effect of volume expansion immediately at the end of infusion. We demonstrated a rapid CI reduction after this time point in all responders. RAP decreased after volume expansion as compared to T1 values. PAOP and MAP were similar to baseline values at T3. Our findings suggest that post- 
Table 2 Time-course of hemodynamic variables (all patients)

\begin{tabular}{lllll}
\hline Variables & T0 (baseline) & T1 (30 min) & T2 (60 min) & T3 (90 min) \\
\hline RAP $(\mathrm{mmHg})$ & $8.20 \pm 3.02$ & $10.5 \pm 3.17^{*}$ & $9.0 \pm 3.06^{*,+}$ & $9.10 \pm 4.00^{*,+}$ \\
PAOP $(\mathrm{mmHg})$ & $8.52 \pm 3.16$ & $10.13 \pm 3.71^{*}$ & $8.81 \pm 3.15^{+}$ & $8.67 \pm 3.36^{+}$ \\
$\mathrm{MAP}(\mathrm{mmHg})$ & $73.70 \pm 8.18$ & $81.70 \pm 9.64^{*}$ & $77.95 \pm 10.28^{*}$ & $77.60 \pm 13.05$ \\
$\mathrm{HR}($ beats/min) & $109 \pm 18.48$ & $106.15 \pm 18.11$ & $107.35 \pm 19.20$ & $107.55 \pm 19.45$ \\
$\mathrm{SVO}_{2}(\%)$ & $66.30 \pm 9.03$ & $69.07 \pm 7.98^{*}$ & & \\
Lactate $(\mathrm{mg} / \mathrm{dL})$ & $3.44(1.92$ to 5.47$)$ & $3.0(1.86$ to 5.53$)$ & & \\
$\mathrm{Hb}(\mathrm{g} / \mathrm{dL})$ & $9.59 \pm 1.62$ & $9.17 \pm 1.80$ & & \\
\hline
\end{tabular}

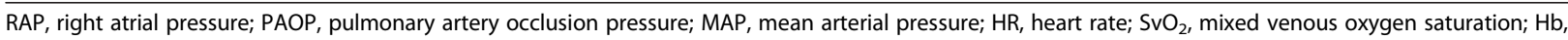
hemoglobin. ${ }^{*} p<0.05$ versus baseline, ${ }^{+} p<0.05$ versus T1. Data are expressed as means (SD) or medians (IQR 25 th to 75 th percentile).

resuscitation volume expansion in responders with circulatory shock has limited impact.

Our study was performed after the resuscitation phase. It is unclear whether hemodynamic effects would be sustained for longer in the initial resuscitation phase. Hypotensive septic patients who received $5 \mathrm{~mL} / \mathrm{kg}$ of normal saline over $15 \mathrm{~min}$ had a sustained increase in CO within $120 \mathrm{~min}$ [30]. However, experimental models of septic shock suggest different results $[31,32]$. Our findings allow us to speculate that repeated volume expansions would be required in responders to sustain CO. Interestingly, studies performed in the context of goal-directed therapy in the perioperative period demonstrated that minimizing stroke volume variation by volume loading, and thus sustaining $\mathrm{CO}$, was associated with increased fluid administration [33-36].
We can suggest that we should be more judicious in pursuing volume expansion in the post-resuscitation phase, even in responders. Excessive intravenous fluid therapy leading to positive fluid balances and interstitial edema could be associated with adverse outcomes in critically ill patients [37-40]. In contrast to hypodynamic circulation, as seen in early severe sepsis [41], late-phase patients usually have elevated RAP, CO, and mixed venous oxygen saturation $\left(\mathrm{SvO}_{2}\right)$ [42,43]. It has been suggested that the preferred use of vasoactive drugs may be an acceptable approach for such late-phase patients [39].

The current study has an important strength. In contrast with previous studies, we described the hemodynamic effects of volume expansion according to a fluid responsiveness status (CI response to volume expansion). Previous

Table 3 Time-course of hemodynamic variables according to fluid responsiveness status

\begin{tabular}{|c|c|c|c|c|c|}
\hline Variable & & T0 (baseline) & T1 (30 min) & $\mathrm{T} 2$ (60 $\mathrm{min})$ & T3 (90 min) \\
\hline \multirow[t]{2}{*}{$\mathrm{Cl}\left(\mathrm{L} / \mathrm{min} / \mathrm{m}^{2}\right)$} & $\mathrm{R}$ & $2.84 \pm 0.61$ & $3.57 \pm 0.65^{*}$ & $3.19 \pm 0.69^{*,+}$ & $3.06 \pm 0.70^{+}$ \\
\hline & $N R$ & $3.40 \pm 0.55$ & $3.59 \pm 0.74$ & $3.31 \pm 0.61$ & $3.24 \pm 0.55$ \\
\hline \multirow[t]{2}{*}{$\mathrm{RAP}(\mathrm{mmHg})$} & $\mathrm{R}$ & $8.54 \pm 3.36$ & $10.23 \pm 3.72^{*}$ & $9.08 \pm 3.59^{*++}$ & $9.23 \pm 3.54^{*+}$ \\
\hline & $N R$ & $7.57 \pm 2.37$ & $9.71 \pm 1.98^{*}$ & $8.86 \pm 1.95^{*,+}$ & $8.86 \pm 2.27^{*,+}$ \\
\hline \multirow[t]{2}{*}{ PAOP $(\mathrm{mmHg})$} & $\mathrm{R}$ & $8.77 \pm 3.30$ & $10.64 \pm 4.03^{*}$ & $8.69 \pm 3.2$ & $8.89 \pm 3.62$ \\
\hline & $N R$ & $8.04 \pm 3.08$ & $9.17 \pm 3.06^{*}$ & $9.01 \pm 3.30$ & $8.26 \pm 3.05$ \\
\hline \multirow[t]{2}{*}{ MAP $(\mathrm{mmHg})$} & $\mathrm{R}$ & $74.62 \pm 6.84$ & $83.92 \pm 8.20^{*}$ & $79.62 \pm 10.94$ & $79.77 \pm 14.02$ \\
\hline & $N R$ & $72.00 \pm 10.63$ & $77.57 \pm 11.36^{*}$ & $74.86 \pm 8.84$ & $73.57 \pm 10.83$ \\
\hline \multirow[t]{2}{*}{ HR (beats/min) } & $\mathrm{R}$ & $107.54 \pm 19.83$ & $105.77 \pm 19.63$ & $107.85 \pm 20.43$ & $108.62 \pm 21.06$ \\
\hline & $N R$ & $111.71 \pm 16.80$ & $106.86 \pm 16.31$ & $106.43 \pm 18.17$ & $105.57 \pm 17.42$ \\
\hline \multirow[t]{2}{*}{ Lactate (mmol/L) } & $\mathrm{R}$ & 2.78 (1.50 to 6.89$)$ & 2.78 (1.56 to 6.72$)$ & & \\
\hline & $N R$ & 3.44 (2.22 to 4.22$)$ & $3.44(2.22$ to 5.11$)$ & & \\
\hline \multirow[t]{2}{*}{$\mathrm{Hb}(\mathrm{g} / \mathrm{dL})$} & $\mathrm{R}$ & $9.36 \pm 1.76$ & $9.34 \pm 2.06$ & & \\
\hline & $N R$ & $10.01 \pm 1.36$ & $8.83 \pm 1.26^{*}$ & & \\
\hline \multirow[t]{2}{*}{$\mathrm{SvO}_{2}(\%)$} & $\mathrm{R}$ & $63.00 \pm 9.08$ & $66.30 \pm 8.30^{*}$ & & \\
\hline & $N R$ & $72.46 \pm 5.02$ & $74.20 \pm 4.01$ & & \\
\hline
\end{tabular}

$\mathrm{R}$, responders; NR, non-responders; $\mathrm{Cl}$, cardiac index; RAP, right atrial pressure; PAOP, pulmonary artery occlusion pressure; MAP, mean arterial pressure; HR, heart rate; $\mathrm{SvO}_{2}$, mixed venous oxygen saturation; $\mathrm{Hb}$, hemoglobin. The groups (R and NR) showed significant $\mathrm{Cl}$ difference over time $(p=0.009)$. The $\mathrm{Cl}$ did not change over time in NR $(p=0,306)$. The groups (R and NR) showed no significant difference over time in RAP, PAOP, MAP, and HR ( $p>0.05)$. Mean values of RAP, PAOP, MAP, and HR were similar between R and NR at T0, T1, T2, and T3 $(p>0.05)$. The groups (R and NR) showed significant difference in SvO $2(p=0.02)$ at T0. The groups ( $\mathrm{R}$ and NR) showed no significant difference in lactate levels $(p=0.72)$ and $\mathrm{Hb}(p=0.46)$ at $\mathrm{TO} .{ }^{*} p<0.05$ versus baseline, ${ }^{+} p<0.05$ versus T1. Data are expressed as means (SD) or medians (IQR 25th to 75th percentile). 
studies assessed these effects using labeling and dilutional methods or static preload parameters as endpoint, which might have limited applicability. Our study also had limitations. The first and main limitation was the sample size. A larger sample might have further strengthened our results. Second, the amount of infused fluid $(500 \mathrm{~mL}$ of crystalloids over $30 \mathrm{~min}$ ) might have not been enough to impact the CI [44]. However, in our study, there was a significant increase in RAP, and the fluid administration was able to significantly increase the $\mathrm{CI}$ in 13 patients. Moreover, in responders whom PPV was measured, the value fell below $12 \%$ in all. Third, we did not have hemoglobin/hematocrit values at different time points (T0, T1, T2, and T3) to calculate changes in blood volume, which could enhance our findings. Fourth, we could not fully assess cardiac function using echocardiography before and after fluid challenge to rule out the presence of previous cardiac dysfunction that could be aggravated by the circulatory shock. Finally, we use a semi-continuous thermodilution technique for determining the $\mathrm{CO}$. This method may underestimate the changes in $\mathrm{CO}$ if it is measured immediately after the fluid infusion. As the patient was followed for $90 \mathrm{~min}$, this limitation most likely did not affect the conclusions of the study.

\section{Conclusions}

In patients with circulatory shock after an initial resuscitation, our findings suggest that the hemodynamic effects of crystalloid administration are not sustained after $60 \mathrm{~min}$, even in responders.

\section{Abbreviations \\ ANOVA: analysis of variance; APACHE II: Acute Physiology and Chronic Health Evaluation II; Cl: cardiac index; CO: cardiac output; Cstat: static respiratory compliance; $\mathrm{FiO}_{2}$ : fraction of inspired oxygen; $\mathrm{Hb}$ : hemoglobin; $\mathrm{HR}$ : heart rate; ICU: intensive care unit; IQR: interquartile range; MAP: mean arterial pressure; $\mathrm{PaO}_{2}$ : partial pressure of oxygen; PAOP: pulmonary artery occlusion pressure; PEEP: positive end-expiratory pressure; PPV: pulse pressure variation; RAP: right atrial pressure; SD: standard deviation; SOFA: Sequential Organ Failure Assessment score; SPSS: Statistical Package for the Social Sciences; $\mathrm{SvO}_{2}$ : mixed venous oxygen saturation}

\section{Competing interests}

The authors declare that they have no competing interests.

\section{Authors' contributions}

FGRF, TSON, and RTL designed and coordinated the study. FGRF, TSON, and ATB contributed to data collection. FGRF and FRM drafted the manuscript. TSON, ATB, RTL, and LCPA revised the article. All authors read and approved the final manuscript.

\section{Acknowledgements}

We thank Creusa Maria Roveri Dal Bó for support with the statistical analyses.

Received: 15 March 2014 Accepted: 14 July 2014

Published: 1 August 2014

\section{References}

1. Marik PE, Monnet $X$, Teboul $J$ : Hemodynamic parameters to guide fluid therapy. Ann Intensive Care 2011, 1(1):1.
2. Funk DJ, Jacobsohn E, Kumar A: Role of the venous return in critical illness and shock: part II-shock and mechanical ventilation. Crit Care Med 2013, 41(2):573-579.

3. Michrd F, Teboul JL: Predicting fluid responsiveness in ICU patients: a critical analysis of the evidence. Chest 2002, 121(6):2000-2008.

4. Monnet X, Teboul JL: Volume responsiveness. Curr Opin Crit Care 2007, 13(5):549-553.

5. Cordemans C, De Laet I, Van Regenmortel N, Schoonheydt K, Dits H, Huber W, Malbrain ML: Fluid management in critically ill patients: the role of extravascular lung water, abdominal hypertension, capillary leak, and fluid balance. Ann Intensive Care 2012, 2(Suppl 1):S1.

6. Durairaj L, Schmidt GA: Fluid therapy in resuscitated sepsis: less is more. Chest 2008, 133(1):252-263.

7. Ragaller MJ, Theilen $\mathrm{H}$, Koch $\mathrm{T}$ : Volume replacement in critically ill patients with acute renal failure. J Am Soc Nephrol 2001, 12(Suppl 17):S33-S39.

8. Freitas FG, Bafi AT, Nascente AP, Assunção M, Mazza B, Azevedo LC, Machado FR: Predictive value of pulse pressure variation for fluid responsiveness in septic patients using lung-protective ventilation strategies. Br J Anaesth 2013, 110(3):402-408.

9. Michard F: Changes in arterial pressure during mechanical ventilation Anesthesiology 2005, 103(2):419-428. quiz 449-415.

10. Hahn RG: Volume kinetics for infusion fluids. Anesthesiology 2010 113(2):470-481.

11. Jacob M, Chappell D, Hofmann-Kiefer K, Helfen T, Schuelke A, Jacob B, Burges A, Conzen P, Rehm M: The intravascular volume effect of Ringer's lactate is below 20\%: a prospective study in humans. Crit Care 2012 16(3):R86.

12. Lobo DN, Stanga Z, Aloysius MM, Wicks C, Nunes QM, Ingram KL, Risch L, Allison SP: Effect of volume loading with 1 liter intravenous infusions of $0.9 \%$ saline, $4 \%$ succinylated gelatine (Gelofusine) and $6 \%$ hydroxyethyl starch (Voluven) on blood volume and endocrine responses: a randomized, three-way crossover study in healthy volunteers. Crit Care Med 2010, 38(2):464-470.

13. Mcllroy DR, Kharasch ED: Acute intravascular volume expansion with rapidly administered crystalloid or colloid in the setting of moderate hypovolemia. Anesth Analg 2003, 96(6):1572-1577. table of contents.

14. Myburgh JA, Mythen MG: Resuscitation fluids. N Engl J Med 2013, 369(25):2462-2463.

15. Woodcock TE, Woodcock TM: Revised Starling equation and the glycocalyx model of transvascular fluid exchange: an improved paradigm for prescribing intravenous fluid therapy. Br J Anaesth 2012, 108(3):384-394.

16. Gondos T, Marjanek Z, Ulakcsai Z, Szabo Z, Bogar L, Karolyi M, Gartner B, Kiss K, Havas A, Futo J: Short-term effectiveness of different volume replacement therapies in postoperative hypovolaemic patients. Eur J Anaesthesiol 2010, 27(9):794-800.

17. Trof RJ, Sukul SP, Twisk JW, Girbes AR, Groeneveld AB: Greater cardiac response of colloid than saline fluid loading in septic and non-septic critically ill patients with clinical hypovolaemia. Intensive Care Med 2010, 36(4):697-701

18. Verheij J, van Lingen A, Beishuizen A, Christiaans HM, de Jong JR, Girbes AR, Wisselink W, Rauwerda JA, Huybregts MA, Groeneveld AB: Cardiac response is greater for colloid than saline fluid loading after cardiac or vascular surgery. Intensive Care Med 2006, 32(7):1030-1038.

19. Kuitunen A, Suojaranta-Ylinen R, Kukkonen S, Niemi T: A comparison of the haemodynamic effects of $4 \%$ succinylated gelatin, $6 \%$ hydroxyethyl starch $(200 / 0.5)$ and $4 \%$ human albumin after cardiac surgery. Scand J Surg 2007, 96(1):72-78

20. Verheij J, van Lingen A, Raijmakers PG, Rijnsburger ER, Veerman DP, Wisselink W, Girbes AR, Groeneveld AB: Effect of fluid loading with saline or colloids on pulmonary permeability, oedema and lung injury score after cardiac and major vascular surgery. Br J Anaesth 2006, 96(1):21-30.

21. Hartog CS, Bauer M, Reinhart $K$ : The efficacy and safety of colloid resuscitation in the critically ill. Anesth Analg 2011, 112(1):156-164.

22. Guidet B, Martinet O, Boulain T, Philippart F, Poussel JF, Maizel J, Forceville $X$, Feissel M, Hasselmann M, Heininger A, Van Aken H: Assessment of hemodynamic efficacy and safety of $6 \%$ hydroxyethylstarch $130 / 0.4$ vs. $0.9 \% \mathrm{NaCl}$ fluid replacement in patients with severe sepsis: the CRYSTMAS study. Crit Care 2012, 16(3):R94.

23. Myburgh JA, Finfer S, Bellomo R, Billot L, Cass A, Gattas D, Glass P, Lipman J, Liu B, McArthur C, McGuinness S, Rajbhandari D, Taylor CB, Webb SA, CHEST 
Investigators; Australian and New Zealand Intensive Care Society Clinical Trials Group: Hydroxyethyl starch or saline for fluid resuscitation in intensive care. N Engl J Med 2012, 367(20):1901-1911.

24. Rioux JP, Lessard M, De Bortoli B, Roy P, Albert M, Verdant C, Madore F, Troyanov S: Pentastarch $10 \%(250 \mathrm{kDa} / 0.45)$ is an independent risk factor of acute kidney injury following cardiac surgery. Crit Care Med 2009, 37(4):1293-1298.

25. Gattas DJ, Dan A, Myburgh J, Billot L, Lo S, Finfer S: Fluid resuscitation with $6 \%$ hydroxyethyl starch (130/0.4 and 130/0.42) in acutely ill patients: systematic review of effects on mortality and treatment with renal replacement therapy. Intensive Care Med 2013, 39(4):558-568.

26. Zarychanski R, Abou-Setta AM, Turgeon AF, Houston BL, Mclntyre L, Marshall JC, Fergusson DA: Association of hydroxyethyl starch administration with mortality and acute kidney injury in critically ill patients requiring volume resuscitation: a systematic review and meta-analysis. JAMA 2013, 309(7):678-688

27. Feissel M, Michard F, Mangin I, Ruyer O, Faller JP, Teboul JL: Respiratory changes in aortic blood velocity as an indicator of fluid responsiveness in ventilated patients with septic shock. Chest 2001, 119(3):867-873.

28. Michard F, Boussat S, Chemla D, Anguel N, Mercat A, Lecarpentier Y, Richard C, Pinsky MR, Teboul $\mathrm{J}$ : Relation between respiratory changes in arterial pulse pressure and fluid responsiveness in septic patients with acute circulatory failure. Am J Respir Crit Care Med 2000, 162(1):134-138.

29. Wiesenack C, Fiegl C, Keyser A, Prasser C, Keyl C: Assessment of fluid responsiveness in mechanically ventilated cardiac surgical patients. Eur J Anaesthesiol 2005, 22(9):658-665.

30. Fang ZX, Li YF, Zhou XQ, Zhang Z, Zhang JS, Xia HM, Xing GP, Shu WP, Shen L, Yin GQ: Effects of resuscitation with crystalloid fluids on cardiac function in patients with severe sepsis. BMC Infect Dis 2008, 8:50

31. Marx G, Pedder S, Smith L, Swaraj S, Grime S, Stockdale H, Leuwer M: Resuscitation from septic shock with capillary leakage: hydroxyethyl starch (130 kd), but not Ringer's solution maintains plasma volume and systemic oxygenation. Shock 2004, 21(4):336-341.

32. Marx G, Cobas Meyer M, Schuerholz T, Vangerow B, Gratz KF, Hecker H, Sumpelmann R, Rueckoldt H, Leuwer M: Hydroxyethyl starch and modified fluid gelatin maintain plasma volume in a porcine model of septic shock with capillary leakage. Intensive Care Med 2002, 28(5):629-635.

33. Lopes MR, Oliveira MA, Pereira VO, Lemos IP, Auler JO Jr, Michard F: Goal-directed fluid management based on pulse pressure variation monitoring during high-risk surgery: a pilot randomized controlled trial. Crit Care 2007, 11(5):R100.

34. Benes J, Chytra I, Altmann P, Hluchy M, Kasal E, Svitak R, Pradl R, Stepan M: Intraoperative fluid optimization using stroke volume variation in high risk surgical patients: results of prospective randomized study. Crit Care 2010, 14(3):R118.

35. Scheeren TW, Wiesenack C, Gerlach H, Marx G: Goal-directed intraoperative fluid therapy guided by stroke volume and its variation in high-risk surgical patients: a prospective randomized multicentre study. J Clin Monit Comput 2013, 27(3):225-233.

36. Buettner M, Schummer W, Huettemann E, Schenke S, van Hout N, Sakka SG: Influence of systolic-pressure-variation-guided intraoperative fluid management on organ function and oxygen transport. Br J Anaesth 2008, 101 (2):194-199.

37. Boyd JH, Forbes J, Nakada TA, Walley KR, Russell JA: Fluid resuscitation in septic shock: a positive fluid balance and elevated central venous pressure are associated with increased mortality. Crit Care Med 2011, 39(2):259-265

38. Vincent JL, Sakr Y, Sprung CL, Ranieri VM, Reinhart K, Gerlach H, Moreno R, Carlet J, Le Gall JR, Payen D: Sepsis in European intensive care units: results of the SOAP study. Crit Care Med 2006, 34(2):344-353.

39. Prowle JR, Echeverri JE, Ligabo EV, Ronco C, Bellomo R: Fluid balance and acute kidney injury. Nat Rev Nephrol 2010, 6(2):107-115.

40. Bihari S, Prakash S, Bersten AD: Post resusicitation fluid boluses in severe sepsis or septic shock: prevalence and efficacy (price study). Shock 2013, 40(1):28-34

41. Rivers E, Nguyen B, Havstad S, Ressler J, Muzzin A, Knoblich B, Peterson E, Tomlanovich M: Early goal-directed therapy in the treatment of severe sepsis and septic shock. N Engl J Med 2001, 345(19):1368-1377.

42. Krafft P, Steltzer H, Hiesmayr M, Klimscha W, Hammerle AF: Mixed venous oxygen saturation in critically ill septic shock patients. The role of defined events. Chest 1993, 103(3):900-906.
43. van Beest PA, Hofstra JJ, Schultz MJ, Boerma EC, Spronk PE, Kuiper MA: The incidence of low venous oxygen saturation on admission to the intensive care unit: a multi-center observational study in The Netherlands. Crit Care 2008, 12(2):R33.

44. Axler O, Tousignant C, Thompson CR, Dalla'va-Santucci J, Drummond A, Phang PT, Russell JA, Walley KR: Small hemodynamic effect of typical rapid volume infusions in critically ill patients. Crit Care Med 1997, 25(6):965-970

doi:10.1186/s13613-014-0025-9

Cite this article as: Nunes et al:: Duration of hemodynamic effects of crystalloids in patients with circulatory shock after initial resuscitation. Annals of Intensive Care 2014 4:25.

\section{Submit your manuscript to a SpringerOpen ${ }^{\circ}$ journal and benefit from:}

- Convenient online submission

- Rigorous peer review

- Immediate publication on acceptance

- Open access: articles freely available online

- High visibility within the field

- Retaining the copyright to your article

Submit your next manuscript at $>$ springeropen.com 